\title{
Are poor people credit-constrained or myopic? Evidence from a South African panel*
}

\author{
Erlend Berg ${ }^{\dagger}$
}

October 2012

\begin{abstract}
Credit constraints are an almost ubiquitous assumption in development economics. Yet direct evidence for credit constraints is limited, and many observations consistent with credit constraints are equally compatible with myopic (non-forward-looking) consumption or precautionary saving. Using household panel data and a source of widely anticipated income in South Africa, this paper tests and rejects the standard consumption model with perfect capital markets. Then, myopic consumption and precautionary saving are tested as alternative explanations for the observed jumps in expenditure. The standard model with credit constraints cannot be rejected in favour of myopic consumption or precautionary saving.
\end{abstract}

Keywords: Credit constraints; household consumption.

\section{Introduction}

Credit market imperfections are central to contemporary development theory, and these imperfections are frequently operationalised as constraints on the amount of credit available to households or firms. But given how often credit constraints are assumed, there is little clear evidence of their presence. In the entry on 'Development economics' in the New Palgrave Dictionary of Economics, Ray (2008) discusses credit market failure and constrained credit as key themes of the field, but admits that

*I am grateful for feedback and suggestions from Tim Besley, Martin Browning, Daniel Clarke, Stefan Dercon, Greg Fischer, Maitreesh Ghatak and participants at the CSAE seminar series and the CSAE Conference 2010. I also thank the Research Council of Norway and the British Academy for financial support.

${ }^{\dagger}$ Centre for the Study of African Economies, Department of Economics, University of Oxford, Oxford OX1 3UQ, United Kingdom, email: erlend.berg@economics.ox.ac.uk, tel: +44 1865281444 , fax: +441865281 447 
'[t]he direct empirical evidence on the existence of credit constraints is surprisingly sparse.'

In fact, many observations that are consistent with constrained credit are equally consistent with alternative explanations, such as myopic ('Keynesian') models in which consumption today depends only on current income or models that permit precautionary saving. In particular, this applies to observations of imperfect consumption smoothing over time.

Apart from the direct interest in establishing whether credit constraints are present, the issue is also related to the question of whether or not poor households can be assumed to be behaving according to the neoclassic paradigm, i.e. whether their behaviour is optimal given the constraints ('poor but rational'). Duflo (2006) argues, based on recent evidence, that the decisions of poor households cannot always be explained by models assuming full rationality. Finding that the consumption behaviour of poor households is not guided by forward planning would have large consequences for the study of development, and being able to distinguish credit constraints from myopic behaviour is therefore important.

Recent work using data from rich countries has exploited the prediction that under standard assumptions and perfect capital markets, there should be no 'jumps' in consumption associated with anticipated increases in income. Such jumps, if present, can be explained either by incorporating credit constraints and/or precautionary saving within the general framework of the standard (forward-looking) consumption model, or by a simple alternative model in which consumption depends only on current income.

However, forward-looking but credit-constrained households should be able to smooth their consumption over anticipated decreases in income. In contrast, myopic consumption functions respond to negative as well as to positive anticipated income changes.

Furthermore, in the standard model, household savings must be zero when credits constraints bind. This can be used to construct a partial test of credit constraints versus precautionary saving as the main mechanism behind consumption 'jumps' within the augmented standard model.

This paper presents a version of the standard consumption model with income uncertainty and constrained credit. An approximate Euler equation is derived and used to predict the effects of anticipated changes in income on the consumption path. It is shown that, in general, expenditure jumps can be explained either by credit constraints or by changes in precautionary saving. This framework is then compared to a simple myopic consumption model in which current consumption 
tracks current income.

Using data from a large panel of black South African households, the response in expenditure to a large anticipated increase in income is investigated. The public, non-contributory Old Age Pension scheme is large compared to median income among black South Africans. The scheme and its age cut-offs are widely known in the population, and take-up is high and well predicted by age.

It is shown that the arrival of the Old Age Pension is associated with large jumps in expenditure, amounting to a rejection of the standard model with perfect credit markets and no uncertainty. However, such jumps are consistent both with an augmented version of the standard model in which credit is constrained or households respond to uncertainty in future consumption, and with a myopic consumption model.

Further evidence is presented using the age-triggered lapse of another public welfare scheme, the child support grant. The lapse of the grant represents a significant and highly predictable decrease in household income. The results show that there is no downward jump in consumption when the grant lapses. This asymmetry in the behavioural response to positive and negative income changes is supportive of the augmented standard model rather than the myopic consumption model.

Finally, within the augmented standard model, the mechanisms of credit constraints and precautionary saving are contrasted. If credit constraints bind, the balance of liquid savings must be zero (or at some other minimum) and therefore cannot decrease at the time of arrival of an anticipated increase in income. But precautionary saving is consistent with households decreasing savings when income increases. Evidence is presented that the tendency to hold positive savings increases at the time of pension eligibility, implying that credit constraints cannot be rejected in favour of precautionary saving effects.

The contributions of this paper are as follows. It is the first paper to employ the asymmetric predictions of anticipated income increases and decreases to test for perfect credit markets and distinguish between credit constraints and myopia in a developing-country context. This methodology is borrowed from existing studies using data from rich countries, but the existing literature does not take into account the possibility that expenditure jumps could also be caused by household responses to uncertainty in future consumption. In a developing country context, the effects of risk on household behaviour cannot be ignored. This paper therefore introduces a partial test between credit constraints and precautionary saving which is, as far as we know, novel: if consumption jumps are driven primarily by uncertainty then households savings might decrease when the anticipated income increase arrives, 
whereas in the case of binding credit constraints, liquid assets should be at a minimum in the period before the income increases and so cannot decrease further. Therefore, finding that the tendency to hold positive savings does not decrease at the time of the anticipated increase in income, this paper cannot reject credit constraints. Though precautionary saving can also not be ruled out as a mechanism, circumstantial evidence is presented which makes the credit constraints explanation more likely. Apart from providing nuanced evidence for the presence of credit constraints, the paper also contributes to the debate on whether people in developing countries are 'poor but rational' by suggesting that they are, indeed, forward-looking but credit-constrained.

The remainder of the paper is organised as follows. The next section provides an overview of related literature. In the theory section, an approximate Euler equation incorporating credit constraints and a precautionary saving motive is derived from a standard consumption model. The predictions from this model are contrasted with those of a basic model of myopic consumption, and the relevant implications for empirical work are drawn out. Next, background information about the Old Age Pension and the Child Support Grant is presented. Thereafter, there is a discussion of the data used, followed by the empirical specifications and results. Finally there is a brief conclusion.

\section{Related literature}

Hall (1978) extended the standard additive consumption model ${ }^{1}$ to the case with stochastic earnings. His influential central finding is that, conditional on today's consumption, no other information available today is predictive of consumption tomorrow. ${ }^{2}$ In other words, consumption should respond to income changes only to the extent that these reflect changes in permanent income.

This prediction has subsequently been exploited by many economists to construct tests of the perfect capital markets assumption. One line of research looks at the effect on consumption of anticipated or unanticipated changes in income (see Browning and Lusardi (1996) for a review). More recently, two papers have argued that households in the United States and Spain adjust their consumption in response to significant and regular changes in annual income, but not in response to

\footnotetext{
${ }^{1}$ These models assume intertemporally additive utility, constant discount factors and consumers who maximise (expected) present discounted utility over the remainder of their lifetime. I follow Browning and Lusardi (1996) in referring to these as standard consumption models, though their origins lie in Modigliani's life-cycle and Friedman's permanent income hypothesis models.

${ }^{2}$ Parker (1999) presents a consumption model that combines Hall's (1978) framework with the durable-goods model of Mankiw (1982), and derives similar predictions.
} 
irregular and small payments because the computational cost of doing so outweighs the potential utility gain. Hsieh (2003) exploits the pre-announced annual payout of petroleum dividends to residents of Alaska as an anticipated change in permanent income. He does not find excess sensitivity of consumption related to the petroleum payout, but on the other hand he confirms earlier results when he finds that the same households do over-react to tax refunds, which are smaller and harder to predict on average. Similarly, Browning and Collado (2001) find that the consumption patterns of Spanish households working in sectors with regular bonus payments do not differ significantly from those of households in other sectors.

The findings in this paper go the other way, indicating that at least in one developing country context, the standard model with perfect capital markets is rejected even with respect to a very large and highly predictable increase in income.

Flavin (1985) tests credit constraints versus myopic consumption using data from the United States, but relies on an instrumental variable technique and aggregate data rather than a source of anticipated income in a panel of households. Altonji and Siow (1987) were possibly the first to point out that forward-looking but credit-constrained agents should react differently to positive and negative changes in income. These papers find no strong evidence of either credit constraints or myopic consumption in the American panel they look at (PSID), whereas this paper provides a strong rejection of the standard model with perfect capital markets in a panel of black South African households.

Shea (1995) uses union contracts to match PSID households to an expected income growth path. He rejects the standard model with perfect capital markets, but finds that consumption reacts more strongly to decreases than to increases in income, which is not in line with either model. Apart from the developing country setting, a much larger data set and (arguably) a cleaner source of income variation, this paper differs from his in incorporating the possible effects of uncertainty.

Deaton (1992) investigates how closely simple 'rules of thumb' can approximate the optimal solution to the standard consumption model. These rules of thumb are partly a function of current income and are thus related to myopic consumption as defined here.

Deaton (1991) studies savings behaviour in the presence of credit constraints, and uses simulations to study the effectiveness of precautionary saving in smoothing household consumption.

Banerjee (2003) surveys the evidence for capital market imperfections in developing countries. One of the most striking pieces of evidence he presents is a wide dispersal between interest rates on saving and borrowing in many parts of the devel- 
oping world. Banerjee and Duflo (2005) call this 'suggestive, albeit indirect, evidence of credit constraints'.

The starting point of an influential paper by Paxson (1992) is the standard model's prediction that the propensity to consume out of unexpected income should be much smaller than for expected income. In other words, a large proportion of windfall gains should be saved. In line with the prediction, she finds that saving among agricultural households in Thailand is responsive to positive income shocks resulting from rainfall variation.

Rosenzweig and Wolpin (1993) assume the presence of credit constraints in their model of farmers in India, and interpret a liquid market in bullocks coupled with a high profitability of bullocks as suggestive evidence that such constraints are indeed present. Banerjee and Duflo (2008) look at a natural experiment in which firms in certain sectors were provided with more credit as a result of a change in government policy. They find that the reform led to increased activity and greater profit among the affected firms. If firms are profit maximisers this implies that they were creditconstrained before the reform. Morduch (1990) tests for credit constraints in rural India.

One strand of the literature looks at self-reported credit constraints. Typically, respondents are flagged as credit-constrained if they either report having tried to borrow and being refused, or if they report being discouraged from applying for credit because they thought they would be refused. For instance, Barham et al. (1996) uses this type of survey information to look at whether the presence of credit co-operatives in regions of Guatemala relaxes credit constraints. Rasmussen (2002) takes a similar approach using data from South Africa. She finds that a high proportion of the households in her sample are credit-constrained.

There is a growing body of literature exploiting the South African Old Age Pension as a source of exogenous income variation. Case and Deaton (1998) look at how various expenditure categories respond to the pension income, but they do not analyse total expenditure, nor do they focus on credit constraints. Edmonds (2006) finds that receiving the pension leads to a decrease in child labour and an increase in school attendance. Duflo (2003) finds that young girls living with a pension-eligible grandmother are in better health than those who do not. Both Edmonds and Duflo argue that their findings are indicative of credit constraints. But their use of cross-section data prevents the inclusion of household fixed effects, and they do not attempt to rule out myopic consumption or precautionary saving as an alternative explanations of their results. 


\section{Consumption models}

\subsection{The standard consumption model with credit constraints and uncertainty}

An agent lives for $T$ periods. ${ }^{3}$ In each period $t$ the agent receives income

$$
y_{t}=\bar{y}_{t}+\epsilon_{t}
$$

where $\bar{y}_{t}$ is deterministic (but may vary with $t$ ) and $\epsilon_{t}$ are shocks with expectation 0 . The agent's problem in period $t$ is to set the consumption path $\left\{c_{\tau}\right\}_{\tau=t}^{T}$ for her remaining lifetime so as to maximise expected lifetime utility,

$$
\mathrm{E}_{t} \sum_{\tau=t}^{T} \delta^{\tau-t} u\left(c_{\tau}\right)
$$

subject to

$$
\begin{aligned}
& w_{\tau}=R w_{\tau-1}+y_{\tau}-c_{\tau} \\
& w_{\tau} \geq \underline{w}_{\tau}
\end{aligned}
$$

for $t \leq \tau \leq T$. Here, $\delta \in(0,1)$ is the discount factor, $R$ is the gross interest rate and $w_{\tau}$ denotes the agent's wealth at the end of period $\tau$. The instantaneous utility function is three times differentiable and satisfies $u^{\prime}>0, u^{\prime \prime}<0$ and $u^{\prime \prime \prime}>0{ }^{4}$

The first set of constraints describes the evolution of wealth: wealth at the end of period $\tau, w_{\tau}$, is the wealth remaining at the end of the previous period, $w_{\tau-1}$, augmented by the gross interest rate $R$, and adjusted for period- $\tau$ labour income and consumption. The starting wealth $R w_{t-1}$ is known at the beginning of period $t$.

The second set of constraints serves two purposes: a bounded end-of-life wealth level $w_{T}$ is required in order to obtain a finite solution. Wealth constraints for earlier periods represent credit constraints.

The first-order condition with respect to consumption at time $t$ is

$$
u^{\prime}\left(c_{t}\right)=\delta R \mathrm{E}_{t} u^{\prime}\left(c_{t+1}\right)+\lambda_{t}
$$

\footnotetext{
${ }^{3} T$ is here taken to be finite, but assuming infinitely lived agents leads to the same result as long as debt is asymptotically bounded.

${ }^{4}$ Assuming $u^{\prime \prime \prime}>0$ makes the agent a precautionary saver. This is a standard assumption and seems intuitive: assuming $u^{\prime \prime \prime}<0$ would make the agent dissave in the current period when faced with future uncertainty.
} 
where $\lambda_{t}$ is the Kuhn-Tucker multiplier for the credit constraint. It is positive if the credit constraint binds in period $t$ and zero otherwise.

Because of the uncertainty in future income, there will also be uncertainty in future consumption. Consumption uncertainty cannot be made precise at this level of generality, but it is always possible to write

$$
c_{t+1}=\overline{c_{t+1}}+e_{t+1}
$$

with $\overline{c_{t+1}}=\mathrm{E}_{t} c_{t+1}$ and $\mathrm{E}_{t} e_{t+1}=0$. Denote $\sigma_{t+1}^{2}=\operatorname{Var}_{t}\left(e_{t+1}\right)$. Then a Taylor expansion and taking expectations yield the approximate Euler equation ${ }^{5}$

$$
u^{\prime}\left(c_{t}\right) \approx \delta R u^{\prime}\left(\overline{c_{t+1}}\right)+\frac{\delta R}{2} \sigma_{t+1}^{2} u^{\prime \prime \prime}\left(\overline{c_{t+1}}\right)+\lambda_{t} .
$$

If there were no credit constraints and no uncertainty in the model, the Euler equation would be just

$$
u^{\prime}\left(c_{t}\right)=\delta R u^{\prime}\left(c_{t+1}\right) .
$$

According to this basic version of the Euler equation, consumption should evolve smoothly according to the magnitude of $\delta R$ and the shape of the utility function. In particular, the consumption path should not depend on the distribution of income over time, and anticipated changes in income should not lead to jumps in consumption.

Compared to the basic version, (1) introduces two extra terms on the right-hand side. The first of these represents the effect of uncertainty. The more uncertainty there is about tomorrow's consumption, the more today's consumption is depressed. This is precautionary saving.

The second extra term is the Kuhn-Tucker multiplier $\lambda_{t}$. It is positive when credit constraints are present and binding in period $t$, again with the effect of depressing current consumption relative to future consumption. Intuitively, if credit constraints prevent the agent from borrowing as much she would like, she is forced to consume less in the current period than full consumption smoothing would imply.

\subsection{Myopic consumption}

In the standard model outlined above, the household takes all future periods into account when determining consumption. One of the key predictions is that households

\footnotetext{
${ }^{5}$ The use of approximate Euler equations to estimate structural parameters has been criticised by Carroll (2001), but he condones their use for testing whether the relationship between the constituent quantities are significant or not.
} 
will smooth consumption over their lifetime.

Contrast this with an alternative framework in which consumption depends only on current income, sometimes referred to as Keynesian consumption. It may seem simplistic as a model of consumer behaviour, but it is useful because the stark present-mindedness represents the opposite extreme to the perfect foresight of the standard model. The assumption of a lack of forward planning may be motivated by bounded rationality, but Duflo (2006) suggests that poverty may additionally distort the normal decision-making process. Low human capital, inadequate nutrition and the stress of having to make decisions that may affect the subsistence of one's family might explain an extreme focus on the present.

More advanced versions of myopic consumption models are considered in the literature, but they share the critical feature that current consumption is a positive function of current-period income. Deaton (1992) considers several rules of thumb of this type, of which his benchmark rule is to 'consume all cash on hand up to mean income, and 30 per cent of any excess.'

\subsection{The response to anticipated income changes}

The standard model with perfect credit markets and no uncertainty predicts a smooth consumption path irrespective of (deterministic) fluctuations in the income stream. If income is known to change from period $t$ onwards, the agent would immediately adjust by borrowing or saving in order to smooth consumption. Consumption 'jumps' in response to anticipated income changes therefore amount to a rejection of the unaugmented standard model.

The standard model augmented with credit constraints leads to an asymmetry in predictions: anticipated increases in income might be associated with consumption jumps, since constrained credit has the effect of depressing today's consumption relative to tomorrow's. However, credit constraints cannot bind when the agent faces an anticipated decrease in income. This is because the technology required to smooth consumption across a decrease in income is savings, not credit.

In contrast, according to the myopic model, consumption should track decreases as well as increases in income. Finding consumption jumps in response to income increases, but not decreases, is therefore supportive of the augmented standard model rather than the myopic model.

Within the augmented standard model as presented here, there are two mechanisms that could explain expenditure jumps (equation 1): binding credit constraints and precautionary saving. ${ }^{6}$ These two mechanisms are in principle non-competing,

\footnotetext{
${ }^{6}$ With precautionary saving, an anticipated increase in income leads to a positive expenditure
} 
i.e. the household could be both prudent and credit-constrained. However, the primary interest here is in whether households face credit constraints. In this context it is pertinent that the two mechanisms lead to different predictions about household savings: savings must be at a minimum and hence cannot decrease when credit constraints bind, but a decrease in savings is consistent with precautionary saving.

The implication is that a decreasing tendency to hold positive savings across an anticipated increase in income would rule out credit constraints as a mechanism and suggest a precautionary saving motive. But an increasing or unchanged tendency to hold positive saving at the time of an anticipated increase in income could be caused by credit constraints and/or precautionary saving. In the latter case, credit constraints cannot be ruled out as mechanism, but nor can a precautionary saving effect.

\section{The Old Age Pension and the Child Support Grant}

The South African Old Age Pension is a non-contributory, means-tested public benefit scheme, originally set up in the 1920s to provide a retirement income for the minority of white workers who did not have pension arrangements through their employer. In 1989, the government committed to removing racial inequalities in the system, and from 1993 onwards the new scheme was fully operational throughout the country. In rural areas, the money is distributed from a sophisticated network of mobile paypoints reaching each beneficiary once a month. Today, the pension is a major source of income ${ }^{7}$ among the poor all over the country, and in many households the main breadwinner is an Old Age Pensioner. See Case and Deaton (1998) for more detail.

To qualify for the pension, the applicant has to be old enough and also pass a means test. Only people whose wealth and income are below certain levels qualify. The means test is set at a level where most white elderly fail to qualify, but a large

jump if the higher income, other things equal, leads to a reduction in consumption uncertainty. It seems reasonable that higher income should lead to a reduction in consumption uncertainty, and it is easy to construct special cases of the model in which this holds. However, it cannot be shown at the level of generality presented here. In other words, in the general setup precautionary saving is a possible explanation for why expenditure jumps at the time of an anticipated increase in income. But there may be model specifications in which precautionary saving would not have this effect. Note that this does not detract from the point that past observations of expenditure jumps in the literature may have been caused by precautionary saving behaviour.

${ }^{7}$ In 2000, the pension paid out ZAR 540 per month. This is approximately 1.7 times the median per-capita total black household income of ZAR 320 per month computed from the Income and Expenditure Survey 2000. 
majority of black elderly easily pass the hurdle. Hence for black people the pension can largely be regarded as a universally available and secure monthly income stream, beginning at the lower qualifying age (60 for women, 65 for men) and continuing until death. It is independent of the economic situation of family members, except the spouse for married pensioners. From an econometric perspective, it provides a convenient source of quasi-exogenous income variation among people around the qualifying age.

Given its popularity, reach and financial importance, the pension is a highly anticipated source of income. The qualifying age limits are also widely known (Duflo, 2003; Case and Deaton, 1998).

The Child Support Grant was introduced in 1998 to replace the earlier state maintenance grant. It is paid to the primary care-giver (usually the mother) of young children. It is in principle means-tested, and a large proportion of black mothers with age-eligible children qualify. Initially it only covered children up to and including the age of six, but from 2002 there was a gradual expansion to older children. For the 2001 and 2002 surveys used in this study, the upper age limit was six years. When the 2003 survey was conducted, the upper age limit was eight years. Grant take-up increased rapidly during the period studied, in part due to considerable effort by the government. In 2002, the grant paid out ZAR 110 per month per child, which is more than one-third of the median per capita household income among blacks. Rosa and Mpokotho (2004) provide more detail on the Child Support Grant.

\section{Data}

Since 2000, Statistics South Africa has conducted a Labour Force Survey twice a year. It is designed as a rotating panel survey, but the longest series of longitudinal household observations is substantially shorter than it could have been, due to several 'fresh starts' in which completely new samples were drawn. This study uses the September 2001, September 2002 and September 2003 waves of the survey. The surveys are nationally representative. Only households headed by a black ('African', in the South African terminology) person are considered here. After dropping 175 households due to missing data on the gender, age or population group of one or more household members, there remains 36,208 households in the panel, of which 11,962 are observed twice and 6,668 are observed three times.

An expenditure variable was constructed as follows. In each of the survey rounds the households were asked, 'What was the total household expenditure in the last 
month? Include everything that the household and its members spent money on, including food, clothing, transport, rent and rates, alcohol and tobacco, school fees, entertainment and any other expenses.' The answer options were: R 0-399, R 400799, R 800-1,199, R 1,200-1,799, R 1,800-2,499, R 2,500-4,999, R 5,000-9,999, R 10,000 or more, 'Don't know' or 'Refuse'. The expenditure variable used in this paper was constructed by taking the midpoint of each interval. For the ' $\mathrm{R} 10,000$ or more' option, expenditure was set to $\mathrm{R} 15,000$. The last two response options were coded as missing values. It is the logarithm of the resulting number that is used here as the measure of monthly household expenditure.

A household is coded as age-eligible for the Old Age Pension if there is at least one woman aged $60+$ or one man aged $65+$ in the household, and age-eligible for the Child Support Grant if at least one child below the upper age limit is present in the household at the time of observation. The validity of age eligibility as a predictor of take-up is confirmed in Figure 1, where take-up of the Old Age Pension is plotted against the age of the oldest male and female household members. Age eligibility is clearly a strong predictor of pension take-up, though perhaps more cleanly for women than for men.

Descriptive statistics are presented in Table 1. Most of the variables appear to be stable over time, but the increasing take-up of the Child Support Grant is discernible.

For the analysis reported in Figure 4 only, data from the Income and Expenditure Survey 2000 were used instead.

\section{Results}

\subsection{The response to an anticipated increase in income}

This section looks at how household expenditure responds to the anticipated income stream from the Old Age Pension. The results can be previewed in Figure 2, in which the logarithm of monthly household expenditure is plotted against the age of the oldest female and male household members. For both sexes, expenditure increases from the age of 20 until it reaches a maximum around the age of 40 for women and a few years later for men, after which it decreases. However, at 60, the age of female pension eligibility, there is a clear break and expenditure as a function of the age of the oldest female seems to rise rapidly before levelling off. There is a similar trend break for men around the age of 65 , though again the onset is perhaps not as cleanly defined. 
The main empirical specification is

$$
Y_{i t}=\alpha_{i}+\mu_{t}+\gamma L_{i t}+X_{i t} \beta+\varepsilon_{i t}
$$

Here, $Y_{i t}$ is the log-expenditure of household $i$ at time (survey) $t$. On the right-hand side, $\alpha_{i}$ is a household fixed effect, $\mu_{t}$ is a time fixed effect, and $L_{i t}$ is an indicator for whether household $i$ receives, or is age-eligible for, the Old Age Pension in year t. $X_{i t}$ is a vector of control variables, and $\varepsilon_{i t}$ is the error term.

The coefficient of interest is $\gamma$. Given the specification, it is only identified within households that move from a non-pension to a pension state or vice versa. Disregarding deaths and other changes in household composition, this will only happen when a female household member turns 60 , or a male household member turns 65 . In the eligibility specification, the identifying assumption is that conditional on household demographics and other controls there is nothing special about turning 60/65 other than that one becomes eligible for the Old Age Pension. This assumes that all other changes to do with 'entering retirement' are either a direct consequence of qualifying for the pension, or are controlled for in the regression.

Throughout the analyses, age eligibility rather than actual take-up will be the preferred right-hand-side variable. This is due to possible endogeneity in the takeup decision: it may be that a person's decision about when to apply for the Old Age Pension is co-determined with other unobserved characteristics that may also impinge on expenditure.

The results are presented in Table 2. All regressions, here and later, include household and time fixed effects, and standard errors are robust and clustered at the level of the primary sampling unit.

In column 1, household log-expenditure is regressed on a dummy variable indicating whether the household receives the Old Age Pension (1) or not (0). The coefficient of interest is positive at .195 and highly significant. This suggests that receipt of the pension increases a household's expenditure by approximately $20 \%$. Column 2 regresses log-expenditure on a binary indicator for whether at least one household member is age-eligible for the pension. The coefficient drops to .160 but remains highly significant. In column 3 , variables indicating the presence of male and female age-eligible household members are included separately. The male and female eligibility coefficients are .147 and .159, respectively. Both are significantly different from zero, but they are not significantly different from each other.

All these coefficients are estimated within households. The fixed effects control for unobservables that are invariant over time, but previous work has suggested that household composition can change in response to pension receipt (Edmonds 
et al., 2004). It has been suggested that mothers with young children are more likely to move in with the grandmother when the latter starts receiving the Old Age Pension, while mothers with older children may leave their children in the care of the grandmother and migrate for work.

This is not a problem for the present purposes, since the main right-hand-side variable, age eligibility, is exogenous to such changes. Changes in household composition is a consumer choice, and if they occur at the time of pension eligibility then they represent another indication of a break in the consumption path: if it were possible to smooth consumption, it would not be necessary to wait for pension eligibility in order to effectuate changes in household composition. Nevertheless, in column 4 a full set of household demographics are included, namely separate variables for the number of male and female family members in the age groups 0-4, 5-14, 15-24, 25-34, 35-44, 45-54 and 55+. In addition, to address any remaining concern that the results are picking up the effect of ageing between 59 and 60 (64 and 65), the age, squared aged and cubed age of the oldest household member are also included. The coefficient drops to 0.090 but remains significant at the $1 \%$ level. The drop in magnitude suggests that some of the observed increase in expenditure at the age of pension eligibility is related to changes in household composition.

This paper uses (log-)expenditure as the main dependent variable, whereas the theory's predictions are in terms of consumption. The two are often the same. However, given the somewhat imprecise wording of the survey question on which the expenditure variable is based, there is a possibility that the expenditure data used may include debt repayment. There may therefore be a concern that the observed increase in expenditure at the age of pension eligibility may reflect the repayment of loans rather than an increase in consumption. However, there are no data on debt principal or repayment with which to investigate this. But households were asked whether they had in the 12 months prior to the interview incurred any debt, and also whether there is a mortgage on their dwelling. One may therefore study the expenditure of households without debt by focusing on the subsample of observations where no debt had been incurred in the past 24 months, and where the dwelling is not mortgaged at any observed point. This rules out short-term debt and the most important type of long-term debt, though non-mortgage debts incurred more than 24 months ago and still outstanding cannot be ruled out.

The restriction reduces the sample size dramatically, but for the remaining households consumption should be closely aligned with expenditure. The results of this regression are reported in column 5. The coefficient remains significant, and is not significantly different from the full-sample result. 
Though the regressions reported so far allow for household fixed effects, the Euler equation suggests that households may be on different consumption trends depending on their discount factor and/or household characteristics. Because some households are observed three times, it is possible to put first-differenced log-expenditure on the left-hand side. The household fixed effects would then capture idiosyncratic household trends, and the regression would test for whether pension eligibility leads to a break in expenditure trend. The result of this regression is reported in column 6 , and the highly significant coefficient of .267 indicates that becoming eligible for the pension increases the year-on-year growth in consumption by just over $30 \%$.

To address any concerns about the strategy of assigning to each household an expenditure equal to the midpoint of the reported expenditure bracket, column 7 presents the results of a random-effects ordered probit regression. As this analysis uses only the ordering of the expenditure categories, nothing is assumed about the distribution of households within each expenditure category. It is clear that pension eligibility has a positive and statistically significant impact on expenditure category.

Some readers may be concerned about the assumption that the effect on expenditure of ageing one year between the age of 59 and 60 (or 64 and 65) is negligible or else follows a trend. Therefore, the log-expenditure variable was also regressed on annual demographic variables for household members within five years of the qualifying age. For each integer $n$ from -5 to 5 , a variable was constructed that counts the number of household members no more than $n$ years younger than the qualifying age. Thus the variable indexed by $n=-5$ equals the number of women aged 55 or more plus the number of men aged 60 or more, and the variable indexed by $n=0$ counts the number of household members who qualify for the pension (i.e. those who are at or above the qualifying age). If qualifying for the pension is linked to increased expenditure but general ageing in this window is not, then one would expect the coefficient on the variable indexed by $n=0$ to be positive, but none of the others.

The specification for this analysis is

$$
Y_{i t}=\alpha_{i}+\mu_{t}+\sum_{n=-5}^{5} b_{n} d_{n i t}+\varepsilon_{i t}
$$

where $d_{n i t}$ is the number of women aged $60+n$ or above, plus the number of men aged $65+n$ or above, in household $i$ at time $t$. Hence $d_{0 i t}$ captures the number of pension-qualifying members of household $i$ at time $t$.

The results are presented graphically in Figure 3. The estimated coefficients are marked by dots, and the bars show the $95 \%$ confidence intervals. It is clear that only 
the coefficient at the qualifying age $(n=0)$ is significantly different from zero, and it is positive. The regression also included household and year fixed effects. Running separate regressions by sex (not reported) yield equivalent results for women, whereas in the male-only specification none of the coefficients are significant.

There may remain a concern that the distinction between consumption and expenditure is not adequately addressed. Therefore, an analysis similar to the one in Figure 3 was undertaken using a different data set. The Income and Expenditure Survey 2000 breaks down financial transactions in more detail, so that it is possible to create a consumption variable that explicitly excludes loan payments or deposits into saving/investment accounts. However, this variable is only available in a crosssection, implying that computing within-household estimates are not possible. The logarithm of annual consumption was regressed on the same set of variables as before, and the results are presented in Figure 4. Standard errors were again robust and clustered at the level of the primary sampling unit.

It is clear that the only variable that is significant is at +1 , and it is positive. This implies that having a female aged $61+$ or a male aged $66+$ significantly increases consumption relative to younger age groups. Though this indicates the presence of a positive discontinuity in consumption as expected, it does seem to occur one year after the qualifying age as opposed to simultaneously with it. A possible explanation for this relates to the way age information was collected for this survey. As well as age, the year of birth was recorded. But it appears that rather than collecting age information separately, it has been calculated by subtracting the year of birth from the year of the survey (2000). However, since the survey took place in October, this will overstate the age for a significant proportion of the sample. It is therefore likely that some people recorded as being 61 years of age were in fact only 60 at the time of the survey. ${ }^{8}$

Because the cross-sectional data set rules out household fixed effects, a similar regression was also run in which household demographics (the same set of variables as before) were controlled for, along with two binary variables indicating the level of education of the household head (indicators for having any education at all and having completed high school). The qualitative results did not change. As above, when the regression was run separately for men and women, the qualitative result was retained for women, but for men there were no significant coefficients.

\footnotetext{
${ }^{8}$ If one assumes that the survey was done in mid-October, and birthdays are uniformly distributed across the year, then $12.5 \%$ of the population will not yet have had their birthday in the current year. However, in the survey less than $2 \%$ of household members appear to not yet have had their birthdays in the survey year, suggesting that age has been overstated by one year for a significant proportion of the sample. This could explain the regression result.
} 
In order to interpret these results, refer back to the Euler equation (1). Basic household demographics are controlled for in column 5, so these cannot account for the expenditure response. Though it is difficult to rule out unobserved characteristics that change over time, the household fixed effects capture anything that is time-invariant at the household level. The Euler terms involving the discount factor and interest rate may be responsible for an increasing or decreasing trend in expenditure, though the year fixed effects will capture any changes that affect the sample as a whole and the first-differenced results allow for household-specific trends.

The results presented here indicate that expenditure responds forcefully to pension age eligibility. The standard explanation for this observation would be that the households faced binding credit constraints the previous year. But if qualifying for the pension is associated with a change in consumption uncertainty (which seems likely) as well as an increase in income, then these results cannot rule out the possibility that the observed change in consumption is related to precautionary saving: the pension income may be associated with some uncertainty since it depends on the survival of the pensioner. Finally, myopic consumption that simply tracks income can also explain these findings.

Some readers may be concerned that a major life change ('retirement') might systematically coincide with the qualifying age for the pension and bias the results. However, for the majority of the black population who are either unemployed or employed in the informal sector, there is no well-defined concept of 'retirement' in the sense of reaching the end of an employment contract. This is illustrated by the fact that only $2.6 \%$ of black women in the $60-64$ age group receive employmentrelated pensions, and the equivalent number for black men in the 65-69 age group is $7.2 \%$. If anything, withdrawal from the labour market is much more likely to be caused by the Old Age Pension income (Ranchhod, 2006), or to have already happened (Bertrand et al., 2003), than to coincide with it in a way that might bias the identified effect on consumption.

\subsection{The response to a decrease in income}

Above, it was found that household expenditure, even when de-trended, responds positively to an anticipated increase in income. This amounts to a rejection of the standard model with perfect capital markets and without precautionary saving.

However, the finding is consistent both with the augmented version of the standard model and with the myopic savings model. An anticipated reduction in income may help distinguish between these models: the myopic consumption model unambiguously predicts that expenditure should decrease in line with income. On the 
other hand, credit constraints should not lead to a break in the consumption path, because the technology required to smooth consumption in this situation is savings, not credit. The effect of the precautionary saving term is again less clear.

This identification strategy relies on the availability of a savings technology. Besley (1995) provides a number of reasons why savings may not be an available or attractive way to achieve smooth consumption in a typical developing country. Anyone can save cash at home or on their person, but the expected return on savings may be zero or negative if there is a considerable risk of loss, appropriation by other household members or theft. Even during apartheid, the South African post office offered a savings account that was available to the whole population. But it is possible that distance or transport cost to the nearest branch, mistrust in the system or illiteracy may have made this product unattractive to many potential savers. Since the end of apartheid, most if not all banks have offered savings accounts available to anyone, though high fees and fear of intimidation may still act as barriers. Informal savings devices, for example in the form of stokvels (ROSCAs), remain popular among black South Africans. Taken together, it seems reasonable to assume that some savings technology was available to the black population in the period studied, even if expected returns may have been low. This is supported by the observation that in the sample, $48 \%$ of households report having savings of some form.

The South African Child Support Grant is available to 'primary carers' (predominantly mothers) of young children. There is a means test which will be ignored here because most black households easily pass it. Instead, the focus is once again on the age cut-offs. Originally, the grant covered any number of biological children up to and including the age of six. So as a first pass, one could look for a drop in household expenditure when children turn seven. If there is such a drop, it could be taken as evidence for myopic behaviour rather than credit constraints.

But this is not entirely satisfactory. In the previous section, identification relied on the assumption that households where a 59-year-old woman (or 64-year-old man) is present is not substantially different from a household with a 60 -year-old woman (or 65-year-old man), except that the latter would be age-eligible for the Old Age Pension. It is less clear that a child with a six-year-old is comparable to a sevenyear-old. Young children develop fast and progress through the educational system, so arguably an age difference of a single year may be associated with considerable changes in household behaviour even if other circumstances were fixed.

For this reason, a change in the age cut-off for the Child Support Grant will be exploited. From 1 April 2003, the upper age limit went up from six to eight years. So in the first two surveys, collected in September 2001 and September 2002, 
only households with children up to and including six years old were age-eligible for a Child Support Grant. But in the final survey round used here, conducted in September 2003, households with children up to and including eight years old were age-eligible.

The situation is illustrated in Figure 5, which shows the proportion of households reporting receipt of the Child Support Grant as a function of the age of the youngest household member. Perhaps the first thing one notices is the rapid expansion in takeup of the grant in the period. For households in which the youngest child is aged 0-6 years, take-up in 2003 was greater than it was in 2002, which in turn was greater than it was in 2001. But the change in the upper age limit for grant eligibility is also clearly visible: in 2001 and 2002, when children up to and including the age of six were eligible, take-up was very low for households in which the youngest child was seven or older. In 2003, when children aged up to and including eight were eligible, similarly low take-up rates were not reached until age nine. The identification of the results presented in this section relies on this change in the eligibility of sevenyear-olds between 2002 and 2003 .

The validity of the identification is corroborated in the first three columns of Table 3. A binary variable indicating whether a household had taken up the Child Support Grant is regressed on the number of children aged seven in the household and an interaction of this variable with an indicator for the year 2003. The identification strategy rests on the assumption that households with seven-year-olds in 2003 are more likely to be in receipt of the Child Support Grant than households with seven-year-olds in 2002, because the former are eligible for the grant whereas the latter are not. This is borne out by the results. Column 1 presents the results of a regression of grant take-up on age-eligibility, controlling for annual and household fixed effects. Column 2 adds yearly count variables for children aged 0-9, and column 3 adds general household demographics. In all three columns, the coefficient on the presence of a child aged seven in 2003 is positive and highly significant, while children aged seven in 2001-2 have no effect.

If the household consumption pattern is determined by myopia, then expenditure for a household with a child aged seven in 2003 should be higher than the expenditure for a household with a child aged seven in 2002, because only the former household is still eligible for the grant. It is true that the former also have higher lifetime earnings, but this should be captured by a household fixed effect, and any macrotrend is captured by year fixed effects.

To test the null hypothesis of forward-looking households, a regression of the 
form

$$
Y_{i t}=\alpha_{i}+\mu_{t}+\gamma C_{i t}+\delta C_{i t} * I_{t=2003}+X_{i t} \beta+\varepsilon_{i t}
$$

was run. Here, $C_{i t}$ denotes the presence of a child age seven in household $i$ and year $t$. The indicator $I_{t=2003}$ is 1 if $t=2003$ and 0 otherwise. Myopic households are expected to reduce consumption at the time of the lapse of the Child Support Grant. Therefore, a household with a seven-year-old in 2002 should decrease its consumption compared to the previous year, whereas a household with a sevenyear-old in 2003 should not. In other terms, the coefficient $\delta$ is positive under the myopic model.

Table 3 presents the results of this regression. In column 4, the regression is run without control variables apart from household and survey fixed effects. The coefficient of interest is negative and not significantly different from zero. In column, 5 further controls are added in the form of variables counting the number of children in age categories from zero up to nine years of age. The coefficient of interest is still not significant. In column 6 , household demographics are added as control variables, but the coefficient of interest changes little and remains insignificant.

To allay fears that the results are driven by the allocation of all households' expenditure to the midpoint of their reported expenditure category, column 7 presents the results of a random-effects ordered probit. This analysis does does not require making any assumption about the distribution of expenditures within the brackets. The results confirm that the presence of a child aged 7 in 2003 is not associated with being in a higher expenditure category.

The coefficient on children aged 7 in 2003 is negative and insignificant for all four expenditure specifications. This is evidence against the myopic model, which predicted positive coefficients.

Though it is likely that the relevant population was reasonably well informed of the basic qualifying requirements for the Child Support Grant, the above analysis implicitly assumes that the change in the qualifying age was also known. The analysis does not permit a distinction between the behaviour of forward-looking but 'surprised' households who learnt that their seven-year-olds were still receiving the grant in 2003, from that of myopic (non-forward-looking) households. Both types of households would be expected to consume more than their counterparts in 2002. The results presented here, a negative coefficient not significantly different from zero, are therefore indicative of forward-looking households that were aware of the changes in the rules. This is plausible given the importance of the grant in South African society. 


\subsection{Credit constraints or precautionary saving?}

The results of the empirical analysis so far are supportive of the augmented standard model rather than either myopic consumption or the basic version of the standard model. The augmented version can explain both the expenditure jump in response to the income increase associated with the pension and the lack of a response to the decrease in income associated with the lapse of the child support grant.

However, the augmented model provides two possible mechanisms, credit constraints and precautionary saving, to explain the expenditure jump in response to the pension. These two mechanisms are not necessarily in opposition, that is, they could both contribute to the jump. Nevertheless, it is of interest whether the response is more likely to be driven by one or the other.

If precautionary saving causes a jump (as opposed to a smoothly increasing slope) in expenditure when income rises predictably, then the change in uncertainty must be related to the new income stream. Given that nearly all age-qualified black people receive the pension, the main risk associated with the pension income is the possibility that the pensioner might die. Intuitively, if households are not certain whether their soon-to-be pensioner is going to survive until the pension arrives, then they might postpone the associated increase in expenditure.

However, according to the World Health Organisation's life tables for South Africa for 2000, the annual death rate for women between the ages of 55 and 60 was only $1.6 \%$. This could be compared to the average death rate between the ages of 30 and 50, which was 1.1\%. For men between the ages of 60 and 65, the annual death rate was higher, $3.5 \%$, compared to $1.5 \%$ between the ages of 30 and 50 . On this basis, it seems unlikely that households would in general regard the receipt of the pension income to be very uncertain in the year before reaching the qualifying age. This suggests that credit constraints rather than precautionary saving is the main driver of the expenditure jump.

A consideration of household savings may provide further evidence. In the model, a household faced with credit constraints ahead of an anticipated increase in income would dis-save in order to smooth consumption as far as possible, in effect 'borrowing from itself'. Therefore, in the theory, credit constraints cannot bind in a given period unless the household has zero savings in that period. In reality, the minimum savings level may be positive rather than zero, due to 'mental accounting', nonunitary households, a working capital requirement, illiquid assets or other departures from the standard model. But these elaborations do not change the prediction that savings must be at a minimum and hence cannot decrease further if credit constraints bind. With a binding credit constraint, pension take-up should therefore 
be associated with an increase, or at least not a decrease, in the propensity to hold positive savings.

On the other hand, assume that the household does not face binding credit constraints and that the jump in consumption is entirely due to precautionary saving behaviour. This is consistent with a decrease in saving when the income increase arrives.

These considerations suggest a partial test between the two mechanisms: If the incidence of positive savings decreases when income increases, then this would rule out credit constraints as a mechanism in favour of a precautionary saving effect. If, however, the incidence of positive savings is constant or increases, then neither credit constraints nor precautionary saving can be ruled out econometrically.

Binary information on savings is available in the data. Each household is asked (yes/no responses only) whether it possesses each of the following types of assets: bank savings accounts, stokvels (ROSCAs), pension plans or retirement annuities, unit trusts, stocks or shares, cash loans expected to be repaid, life insurance, or any other savings. No amounts are provided, but it is possible to construct an overall savings indicator as follows: the household is coded as having positive savings (of any form) if it answered 'yes' to at least one of these options, otherwise not.

Table 4 presents the results of regressions where the dependent variable is the binary savings indicator. Regressing the savings indicator on pension take-up in column 1 yields a positive and highly significant coefficient estimate of .07. Regressing the savings indicator on pension eligibility in column 2 results in a smaller coefficient of .038, but it remains significant at the $1 \%$ level. In column 3 , male and female age eligibility are considered separately. The female coefficient is .040 and highly significant, whereas the male coefficient drops to .023 and is not significantly different from zero. Column 4 presents the results of a regression in which the sample is restricted to observations of households that did not incur any debt in the last 12 months prior to the survey. The coefficient on pension eligibility is .034 and marginally significant. Including a full set of household controls and linear, square and cubic age of oldest households members and using the full sample in column 5 results in a positive and significant coefficient of .04.

One potential issue with these findings is related to how the respondents understand the question about savings, in particular the last option, 'Any other savings'. There may be a tendency not to count modest amounts of cash kept in a purse or wallet as savings, whereas the same amount held in a bank account may be thought of as such. The resulting measurement error may lead to under-reporting of savings for those households that do not use a bank account or other non-cash savings tech- 
nologies. If households are less likely to hold their savings in cash after the increase in income, then an estimate of the effect of the income on savings may be biased upwards. However, using 'Any other savings' on its own as an alternative dependent variable does not change the qualitative results (not reported).

In summary, the savings indicator for the average household seems to increase in response to the increased income. There is therefore no evidence of a decline in savings at the age of pension eligibility, implying that binding credit constraints cannot be rejected. However, on these grounds only, precautionary saving in addition to or instead of credit constraints cannot be ruled out either. But given the relative certainty of receiving the income stream discussed above, and the likelihood that consumption uncertainty is reduced rather than increased with the receipt of the pension, arguably the context suggests that credit constraints rather than precautionary saving is the main mechanism behind the observed violation of the unaugmented standard model.

\section{Conclusion}

The assumption of constrained credit is a staple of economic development theory. However, many findings consistent with credit constraints are equally compatible with precautionary savings or myopic consumption. This paper tests and rejects the standard model with perfect capital markets using data on a panel of black South African households. It also presents evidence that credit constraints, rather than precautionary saving or myopic consumption, drive the observed excess sensitivity of consumption to anticipated income changes.

At the micro-level, inefficient credit markets hamper consumption smoothing and restrain production through inefficient allocation of resources and investments. At the macro-level, these investment misallocations are widely believed to impede growth. Credit markets matter for development, and effective development policy must be sensitive to the precise mechanisms that determine consumption behaviour.

\section{References}

J. G. Altonji and A. Siow. Testing the response of consumption to income changes with (noisy) panel data. Quarterly Journal of Economics, 102(2):293-328, 1987.

A. V. Banerjee. Contracting Constraints, Credit Markets, and Economic Development. Advances in Economics and Econometrics: Theory and Applications: Eighth World Congress of the Econometric Society, 2003. 
A. V. Banerjee and E. Duflo. Growth Theory through the Lens of Economic Development. In P. Aghion and S. N. Durlauf, editors, Handbook of Economic Growth, volume 1A, chapter 7. North-Holland, Amsterdam, 2005.

A. V. Banerjee and E. Duflo. Do Firms Want to Borrow More? Testing Credit Constraints Using a Directed Lending Program. Working paper, 2008.

B. L. Barham, S. Boucher, and M. R. Carter. Credit constraints, credit unions, and small-scale producers in Guatemala. World Development, 24(5):793-806, 1996.

M. Bertrand, S. Mullainathan, and D. Miller. Public policy and extended families: Evidence from pensions in south africa. The World Bank Economic Review, 17 (1):27-50, 2003.

T. Besley. Nonmarket Institutions for Credit and Risk Sharing in Low-Income Countries. The Journal of Economic Perspectives, 9(3):115-127, 1995.

M. Browning and M. D. Collado. The Response of Expenditures to Anticipated Income Changes: Panel Data Estimates. American Economic Review, 91(3):681692, 2001.

M. Browning and A. Lusardi. Household saving: Micro theories and micro facts. Journal of Economic Literature, 34(4):1797-1855, 1996.

C. D. Carroll. Death to the log-linearized consumption euler equation! (and very poor health to the second-order approximation). Advances in Macroeconomics, 1 (1), 2001.

A. Case and A. Deaton. Large cash transfers to the elderly in south africa. Economic Journal, 108(450):1330-1361, 1998.

A. Deaton. Saving and Liquidity Constraints. Econometrica, 59(5):1221-48, 1991.

A. Deaton. Household saving in LDCs: Credit markets, insurance and welfare. The Scandinavian Journal of Economics, 94(2):253-273, 1992.

E. Duflo. Grandmothers and Granddaughters: Old-Age Pensions and Intrahousehold Allocation in South Africa. The World Bank Economic Review, 17(1):1-25, 2003.

E. Duflo. Poor but rational? In A. V. Banerjee, R. Bénabou, and D. Mookherjee, editors, Understanding Poverty, pages 367-78. Oxford University Press, New York, 2006. 
E. V. Edmonds. Child labor and schooling responses to anticipated income in South Africa. Journal of Development Economics, 81(2):386-414, 2006.

E. V. Edmonds, K. Mammen, and D. Miller. Rearranging the family? household composition responses to large pension receipts. Journal of Human Resources, XL(1), 2004.

M. Flavin. Excess sensitivity of consumption to current income: liquidity constraints or myopia? Canadian Journal of Economics, 18(1):117-136, 1985.

R. E. Hall. Stochastic Implications of the Life Cycle-Permanent Income Hypothesis: Theory and Evidence. The Journal of Political Economy, 86(6):971-987, 1978.

C. T. Hsieh. Do Consumers React to Anticipated Income Changes? Evidence from the Alaska Permanent Fund. American Economic Review, 93(1):397-405, 2003.

N. G. Mankiw. Hall's Consumption Hypothesis and Durable Goods. Journal of Monetary Economics, 10(3):417-425, 1982.

J. Morduch. Risk, Production and Saving: Theory and Evidence from Indian Households. Manuscript, Harvard University, 1990.

J. A. Parker. The reaction of household consumption to predictable changes in social security taxes. American Economic Review, 89(4):959-973, September 1999.

C. Paxson. Using Weather Variability to Estimate the Response of Savings to Transitory Income in Thailand. American Economic Review, 82(1):15-33, 1992.

V. Ranchhod. The effect of the south african old age pension on labour supply of the elderly. South African Journal of Economics, 74(4):725-744, 2006.

K. Rasmussen. Securing consumption in low-income households: An empirical study of coping with shocks amongst black households in the KwaZulu-natal province of south africa 1993-1998. Unpublished Masters thesis, University of Copenhagen, Denmark, 2002.

D. Ray. Development economics. In S. N. Durlauf and L. E. Blume, editors, The New Palgrave Dictionary of Economics. Palgrave Macmillan, second edition, 2008.

S. Rosa and C. Mpokotho. Extension of the child support grant to children under 14 years: Monitoring report. Children's Institute, University of Cape Town, 2004. 
M. R. Rosenzweig and K. I. Wolpin. Credit Market Constraints, Consumption Smoothing, and the Accumulation of Durable Production Assets in Low-Income Countries: Investments in Bullocks in India. The Journal of Political Economy, 101(2):223-244, 1993.

J. Shea. Union contracts and the life-cycle/permanent-income hypothesis. The American Economic Review, 85(1):pp. 186-200, 1995. ISSN 00028282. 
Figure 1. Household take-up of the Old Age Pension by age of oldest member.

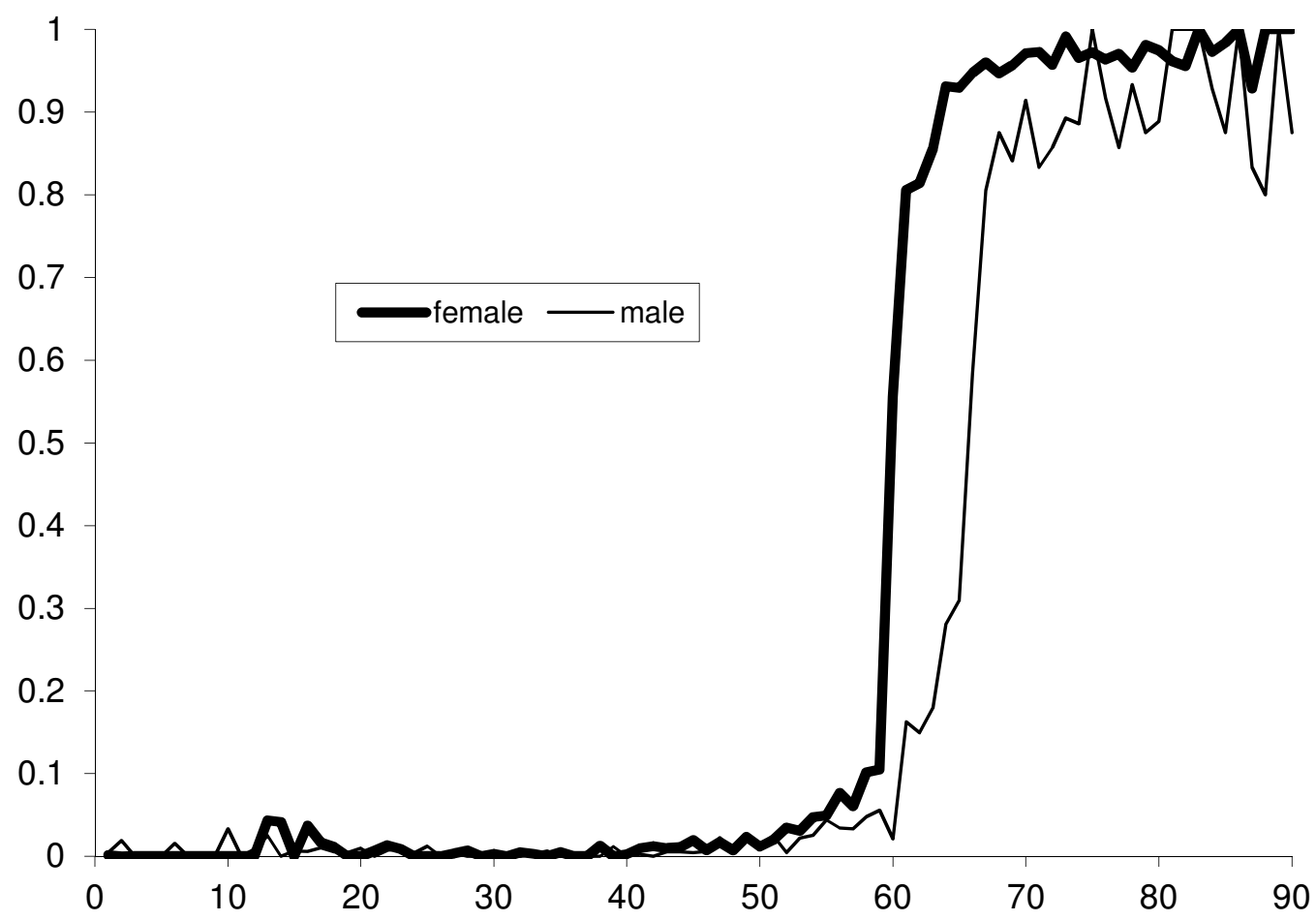

The thick line shows the fraction of households that receive the Old Age Pension, as a function of the age of the oldest female household member. In order to focus on take-up as a function of female eligibility, households with men aged 55+ are excluded from this graph. Similarly, the thin line shows the household take-up rate of the pension as a function of the age of the oldest male household member. Households with women aged $55+$ are excluded from the graph. Recall that women are age-eligible from the age of 60 , and men from the age of 65 . The data is from the September 2003 survey. 
Figure 2. Log expenditure by age of oldest woman/man.

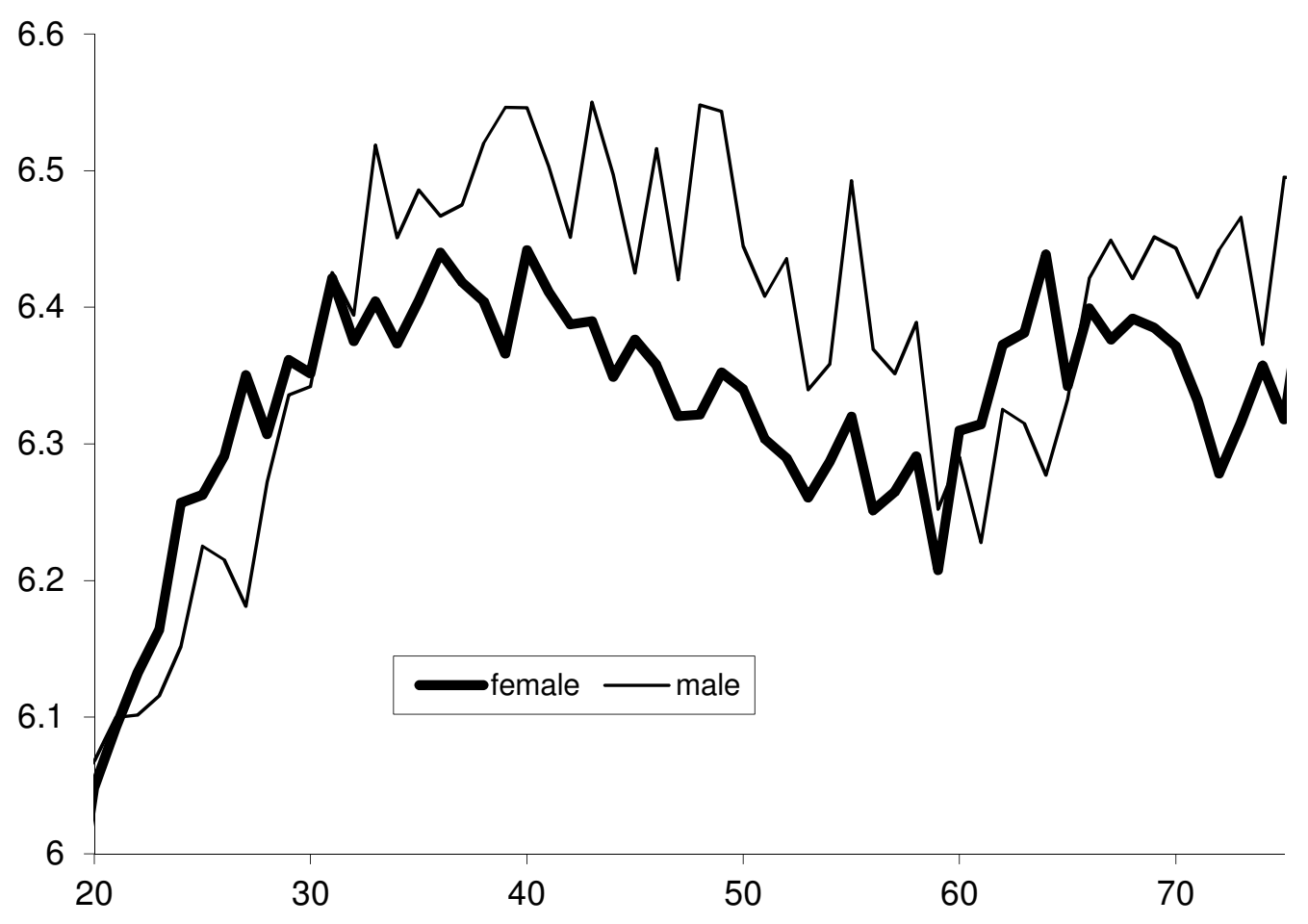

The thick (thin) line shows the average of the logarithm of monthly expenditure as a function of the age of the oldest female (male) household member. The chart pools data for all three survey waves. 
Figure 3. Expenditure by annual age coefficients around the Old Age Pension qualifying age.

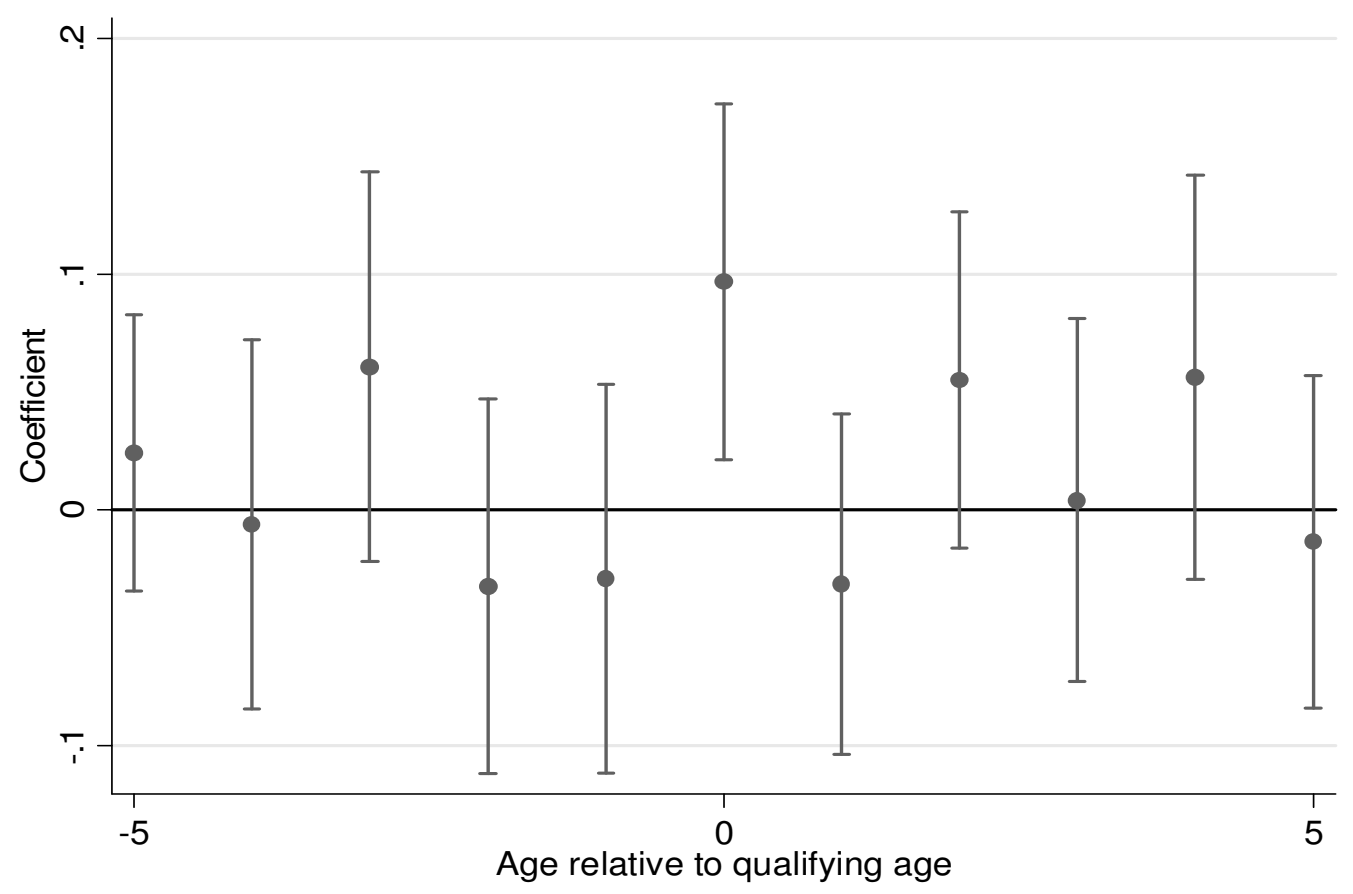

The figure is based on a regression of log annual household expenditure on the number of household members a certain number of years away from pension qualification and above. For example, the left-most estimate at $n=-5$ is the effect on expenditure of the number of household members aged 55 or above (for women) or 65 or above (for men). The only significant co-efficient is the one at $n=0$, measuring the effect of the number of pensionqualified men (65+) and women (60+) in the household. This finding corroborates the assumption that the effects of pure ageing on expenditure is negligible compared to that of being qualified for the pension. Including household demographics and education of the household head does not change the qualitative result that only the coefficient at 0 is positive and significant. These regressions pool data on men and women. 
Figure 4. Expenditure by annual age coefficients around the Old Age Pension qualifying age.

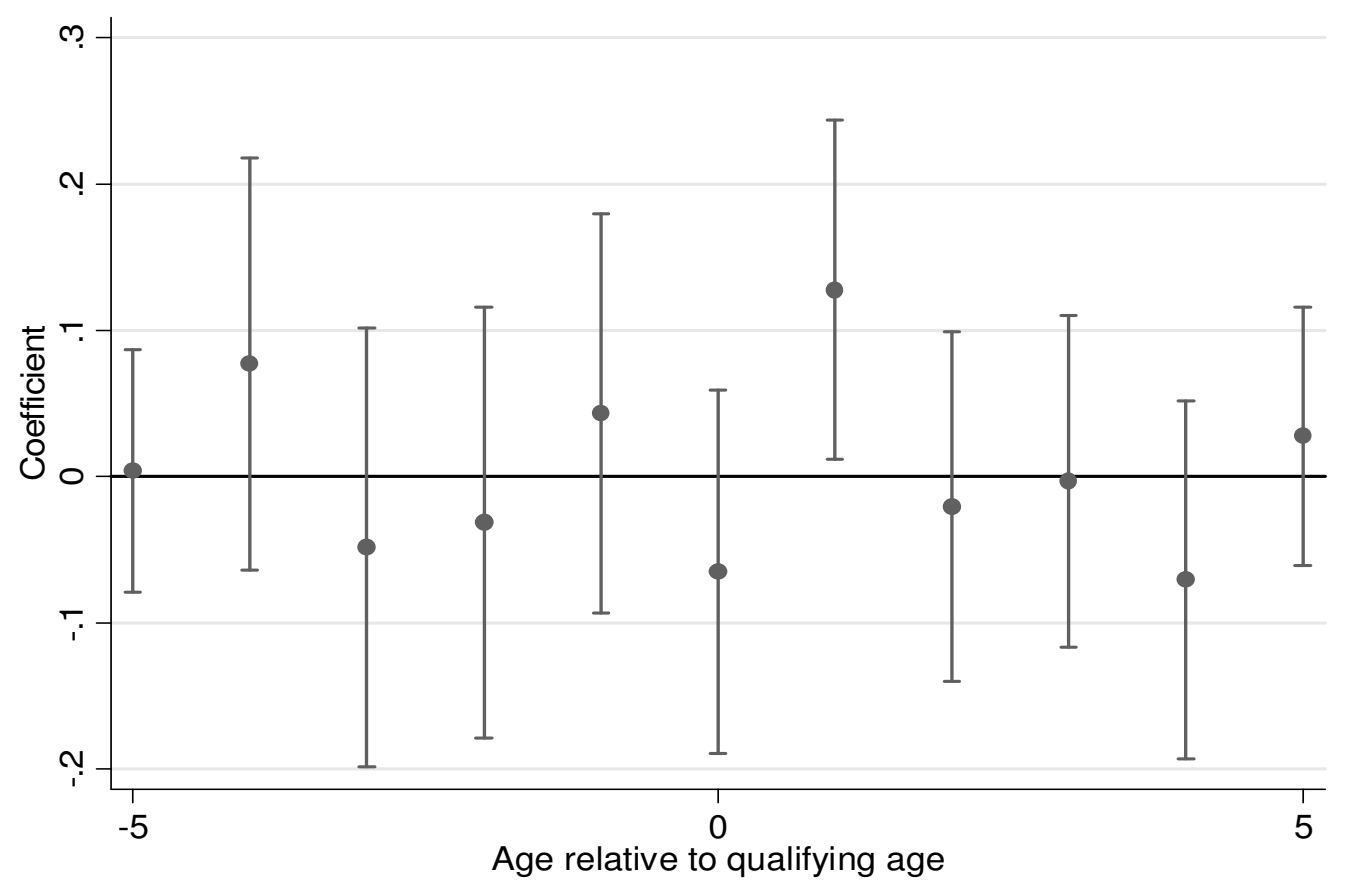

The plot is similar to Figure 3, but based on data from the 2000 Income and Expenditure Survey. This makes it easier to isolate consumption as opposed to expenditure, but the data are only cross-sectional. The above chart is based on a regression of log annual household expenditure on household members a certain number of years away from pension qualification. Including household demographics and education of the household head does not change the qualitative result that the variable at +1 is positive and uniquely significant. The significance at +1 rather than at 0 may be due to age being systematically understated in the survey. The regression pools data on men and women. 
Figure 5. Take-up of Child Support Grant by age of youngest household member.

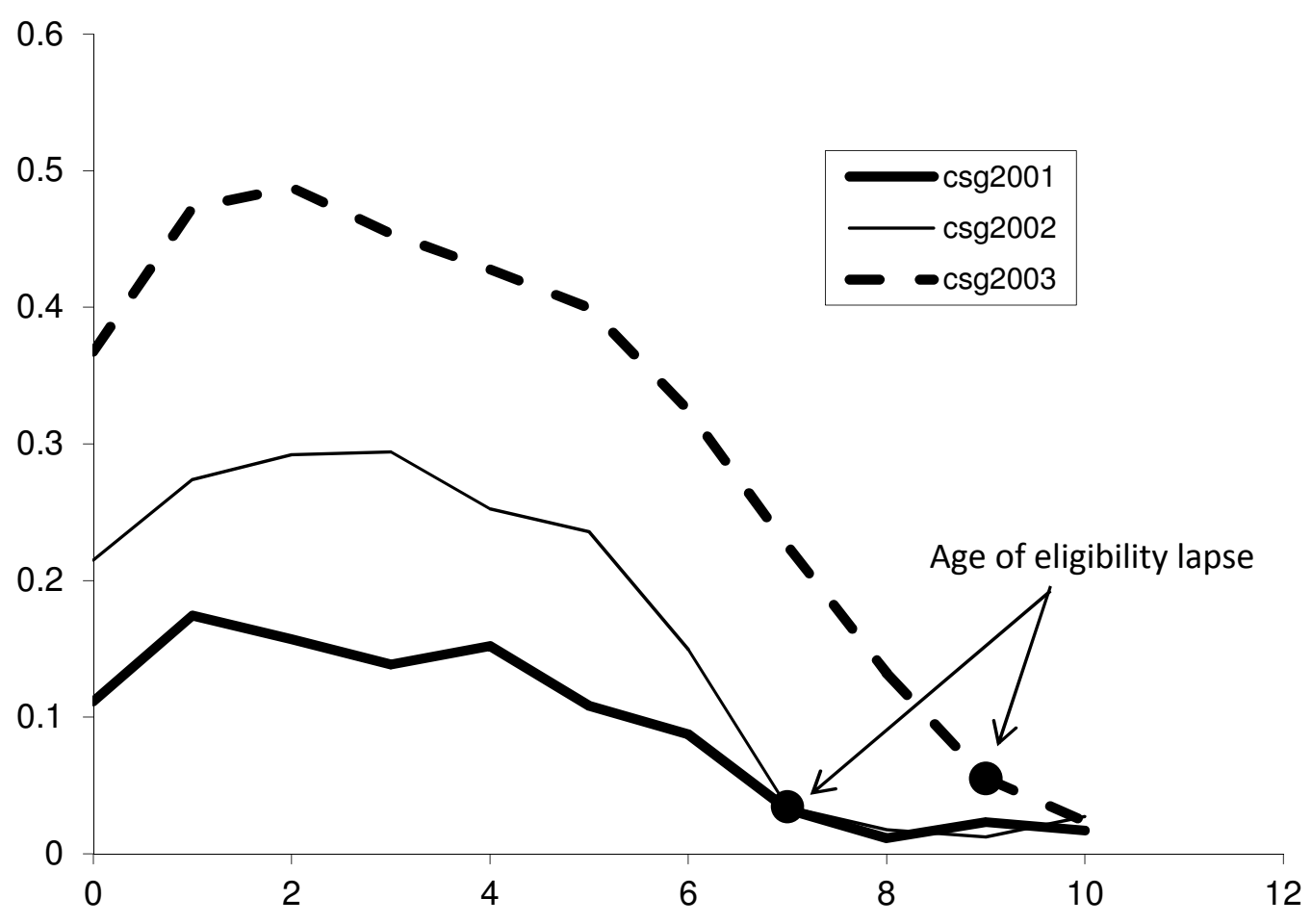

The take-up rate of the Child Support Grant, by the age of the youngest child in the household. The rapidly increasing popularity of the programme between 2001 and 2003 is clear, as is the expansion in age eligibility from 0-6 years in 2001 and 2002 to $0-8$ years in 2003. 
Table 1. Descriptive statistics.

\begin{tabular}{|c|c|c|c|}
\hline & 2001 & 2002 & 2003 \\
\hline Log monthly expenditure & $\begin{array}{l}6.22 \\
{[.90]}\end{array}$ & $\begin{array}{r}6.28 \\
{[.93]}\end{array}$ & $\begin{array}{r}6.40 \\
{[.92]}\end{array}$ \\
\hline The household receives the Old Age Pension & $\begin{array}{c}0.20 \\
{[.40]}\end{array}$ & $\begin{array}{c}0.21 \\
{[.41]}\end{array}$ & $\begin{array}{c}0.21 \\
{[.40]}\end{array}$ \\
\hline A household member is age-eligible for the pension & $\begin{array}{c}0.21 \\
{[.41]}\end{array}$ & $\begin{array}{c}0.22 \\
{[.41]}\end{array}$ & $\begin{array}{c}0.21 \\
{[.41]}\end{array}$ \\
\hline A female household member is age-eligible for the pension & $\begin{array}{c}0.18 \\
{[.38]}\end{array}$ & $\begin{array}{c}0.18 \\
{[.39]}\end{array}$ & $\begin{array}{c}0.18 \\
{[.38]}\end{array}$ \\
\hline A male household member is age-eligible for the pension & $\begin{array}{c}0.07 \\
{[.26]}\end{array}$ & $\begin{array}{c}0.07 \\
{[.25]}\end{array}$ & $\begin{array}{c}0.07 \\
{[.25]}\end{array}$ \\
\hline The household receives the Child Support Grant & $\begin{array}{r}0.06 \\
{[.23]}\end{array}$ & $\begin{array}{r}0.10 \\
{[.30]}\end{array}$ & $\begin{array}{c}0.17 \\
{[.37]}\end{array}$ \\
\hline The household has savings of any form (binary) & $\begin{array}{r}0.46 \\
{[.50]}\end{array}$ & $\begin{array}{l}0.48 \\
{[.50]}\end{array}$ & $\begin{array}{c}0.51 \\
{[.50]}\end{array}$ \\
\hline Household size & $\begin{array}{c}3.98 \\
{[2.79]}\end{array}$ & $\begin{array}{c}3.98 \\
{[2.78]}\end{array}$ & $\begin{array}{c}3.76 \\
{[2.65]}\end{array}$ \\
\hline Observations & 21,107 & 20,043 & 20,356 \\
\hline $\begin{array}{l}\text { Number of observations } \\
\text { Number of households } \\
\text { Number of households observed twice } \\
\text { Number of households observed three times }\end{array}$ & $\begin{array}{r}61,506 \\
36,208 \\
11,962 \\
6,668\end{array}$ & & \\
\hline
\end{tabular}


Table 2. Expenditure response to the Old Age Pension.

\begin{tabular}{|c|c|c|c|c|c|c|c|}
\hline Dependent variable & $\begin{array}{c}1 \\
\text { Expend- } \\
\text { iture }\end{array}$ & $\begin{array}{l}2 \\
\text { Expend- } \\
\text { iture }\end{array}$ & $\begin{array}{c}3 \\
\text { Expend- } \\
\text { iture }\end{array}$ & $\begin{array}{c}4 \\
\text { Expend- } \\
\text { iture }\end{array}$ & $\begin{array}{l}5 \\
\text { Expend- } \\
\text { iture }\end{array}$ & 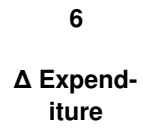 & $\begin{array}{c}7 \\
\text { Expend- } \\
\text { iture }\end{array}$ \\
\hline Household receives the pension & $\begin{array}{l}.195^{\star \star *} \\
{[.0199]}\end{array}$ & & & & & & \\
\hline Household is age-eligible for the pension & & $\begin{array}{l}.160^{* * *} \\
{[.0203]}\end{array}$ & & $\begin{array}{l}.090^{* * *} \\
{[.0305]}\end{array}$ & $\begin{array}{c}.162^{* *} \\
{[.0740]}\end{array}$ & $\begin{array}{l}.267^{\star * *} \\
{[.0633]}\end{array}$ & $\begin{array}{l}.141^{* \star *} \\
{[.017]}\end{array}$ \\
\hline A female household member is age-eligible for the pension & & & $\begin{array}{l}.159^{* * *} \\
{[.0210]}\end{array}$ & & & & \\
\hline A male household member is age-eligible for the pension & & & $\begin{array}{l}.147^{\star * *} \\
{[.0265]}\end{array}$ & & & & \\
\hline Household fixed effects & Yes & Yes & Yes & Yes & Yes & Yes & $\mathrm{RE}$ \\
\hline Year fixed effects & Yes & Yes & Yes & Yes & Yes & Yes & Yes \\
\hline Household demographics & No & No & No & Yes & No & No & No \\
\hline Sample & Full & Full & Full & Full & No debt & Full & Full \\
\hline Observations & 60552 & 60578 & 60578 & 60578 & 8589 & 24159 & 60578 \\
\hline Households & 35893 & 35905 & 35905 & 35905 & 4176 & 17762 & 35905 \\
\hline
\end{tabular}

Notes: Linear regressions, except in column 7. The dependent variable in columns 1-5 is the logarithm of monthly household expenditure. In column 6 it is the first-differenced logarithm of monthly household expenditure. In column 4, controls are included for the number of female and male household members in each of the age groups $0-4,5-14,15-24,25-34,35-44,45-54$ and 55+, as well as the age, squared age and cubed age of the oldest household member. In column 5 , the sample is restricted to those households who report not taking out any debt in the past 24 months and not having a mortgage. Robust standard errors, shown in brackets, are clustered at the level of the survey primary sampling unit. Column 7 shows the results of a random-effects ordered probit regression. ${ }^{\star \star *}$ significant at $1 \%$, ${ }^{* \star}$ significant at $5 \%,{ }^{*}$ significant at $10 \%$. 
Table 3. Response in expenditure to expansion in Child Support Grant eligibility.

\begin{tabular}{|c|c|c|c|c|c|c|c|}
\hline \multirow[b]{2}{*}{ Dependent variable } & 1 & 2 & 3 & 4 & 5 & 6 & 7 \\
\hline & \multicolumn{3}{|c|}{ Grant take-up (binary) } & \multicolumn{4}{|c|}{ Log monthly expenditure } \\
\hline Presence of child aged 7 & $\begin{array}{c}-0.00701 \\
{[.011]}\end{array}$ & $\begin{array}{l}0.0249 \\
{[.0154]}\end{array}$ & $\begin{array}{l}0.0224 \\
{[.0154]}\end{array}$ & $\begin{array}{c}0.032 \\
{[.0213]}\end{array}$ & $\begin{array}{c}0.000601 \\
{[.0331]}\end{array}$ & $\begin{array}{c}-0.00704 \\
{[.0329]}\end{array}$ & $\begin{array}{l}-0.0236 \\
{[.0469]}\end{array}$ \\
\hline Presence of child aged 7 in 2003 & $\begin{array}{l}.141^{* \star \star} \\
{[.0182]}\end{array}$ & $\begin{array}{l}.168^{\star * *} \\
{[.0178]}\end{array}$ & $\begin{array}{l}.167^{\star * *} \\
{[.0178]}\end{array}$ & $\begin{array}{l}-0.0416 \\
{[.0328]}\end{array}$ & $\begin{array}{l}-0.0302 \\
{[.0332]}\end{array}$ & $\begin{array}{c}-0.03 \\
{[.0329]}\end{array}$ & $\begin{array}{l}-0.0487 \\
{[.0476]}\end{array}$ \\
\hline Household and year fixed effects & Yes & Yes & Yes & Yes & Yes & Yes & $R E /$ Yes \\
\hline Controls for number of children aged $0,1,2, \ldots, 9$ & No & Yes & Yes & No & Yes & Yes & Yes \\
\hline General household demographics & No & No & Yes & No & No & Yes & No \\
\hline Observations & 61450 & 61450 & 61450 & 60578 & 60578 & 60578 & 60578 \\
\hline Households & 36182 & 36182 & 36182 & 35905 & 35905 & 35905 & 35905 \\
\hline
\end{tabular}

Notes: Linear regressions, except in column 7. Columns 1-3 verify that the presence of a child aged seven in 2003 is associated with a greater probability of receiving the Child Support Grant than the presence of a child aged seven in 2001 or 2002 . In columns 4-6, the logarithm of household expenditure is regressed on a binary variable indicating the presence in the household of a child aged seven, and an indicator for the presence of a child aged seven in 2003. In columns 3 and 6, controls are included for the number of female and male household members in each of the age groups 0-4, 5-14, 15-24, 25-34, 35-44 and 45-54 and 55+. For columns 1-6, robust standard errors, shown in brackets, are clustered at the level of the survey primary sampling unit. Column 7 shows the result of a random-effects ordered probit regression with controls for year and the number of children in each year group up to $9 .{ }^{* \star *}$ significant at $1 \%,{ }^{* *}$ significant at $5 \%,{ }^{*}$ significant at $10 \%$. 
Table 4. Response in household saving behaviour to the Old Age Pension.

$\begin{array}{lllll}1 & 2 & 3 & 4 & 5\end{array}$

Dependent variable: Household has positive savings (binary indicator)

Household receives the pension

Household is age-eligible for then pension

A female household member is age-eligible for the pension

A male household member is age-eligible for the pension

Household fixed effects

Year fixed effects

Household demographics $.0704^{\star \star *}$

[.0132]

5

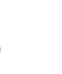

